\title{
Size and Reversal Learning in the Beagle Dog as a Measure of Executive Function and Inhibitory Control in Aging
}

\author{
P. Dwight Tapp, ${ }^{1}$ Christina T. Siwak,${ }^{2}$ Jimena Estrada, ${ }^{2}$ Elizabeth Head,${ }^{3}$ \\ Bruce A. Muggenburg, ${ }^{4}$ Carl W. Cotman, ${ }^{3}$ and Norton W. Milgram ${ }^{1,2,5}$ \\ ${ }^{1}$ Department of Psychology, ${ }^{2}$ Institute of Medical Science, University of Toronto, Scarborough, Ontario, Canada M1C 1A4; ${ }^{3}$ Institute for Brain \\ Aging and Dementia, University of California, Irvine, California 92697-4540, USA; ${ }^{4}$ Lovelace Respiratory Research Institute, Kirtland AFB, \\ Albuquerque, New Mexico, 87115 USA
}

\begin{abstract}
Several studies converge on the idea that executive processes age earlier than other cognitive processes. As part of a larger effort to investigate age-related changes in executive processes in the dog, inhibitory control was measured in young, middle-aged, old, and senior dogs using size discrimination learning and reversal procedures. Compared to young and middle-aged dogs, old and senior dogs were impaired on both the initial learning of the size task and the reversal of original reward contingencies. Impaired performance in the two aged groups was characterized as a delay in learning the correct stimulus-reward contingencies and, among the senior dogs in particular, an increase in perseverative responding. These separate patterns of reversal impairments in the old and senior dogs may reflect different rates of aging in subregions of the frontal cortex.
\end{abstract}

Inhibitory control and performance monitoring are critical executive functions of the human brain which show decreased efficiency during normal aging (McDowd and Oseas-Kreger 1991; McDowd and Filion 1992; Arbuckle and Gold 1993; Zacks and Hasher 1994; McDowd et al. 1995; Sweeney et al. 2001; Nielson et al. 2002; Persad et al. 2002). According to Hasher and Zacks (1988), it is the failure of inhibitory mechanisms that accounts for many aspects of age-related cognitive deficits. They propose that such inhibitory failure disrupts working memory and also interferes with encoding and retrieval processes. Evidence supporting this age-related inhibitory deficit hypothesis has come from studies using go/no-go paradigms (Chao and Knight 1997; Nielson et al. 2002), habituation tasks (Eisenstein et al. 1990; McDowd and Filion 1992), reading and language comprehension tasks (Connelly et al. 1991; Hartman and Hasher 1991; Hamm and Hasher 1992; McDowd et al. 1995; Dywan and Murphy 1996; Faust et al. 1997), negative priming tasks (Hasher et al. 1991; McDowd and OseasKreger 1991; Connelly and Hasher 1993; Kane et al. 1994; McDowd and Filion 1995), and interference paradigms such as the Stroop (1935) task (Hartley 1993; Spieler et al. 1996; West and Baylis 1998; West and Alain 2000). Reductions in the ability to suppress irrelevant or conflicting information or impulses may underlie patterns of cognitive and execu-

${ }^{5}$ Corresponding author.

E-MAIL milgram@psych.utoronto.ca; FAX (416) 287-7642.

Article and publication are at http://www.learnmem.org/cgi/doi/ $10.1101 / \mathrm{lm} .54403$. tive dysfunction even under relatively optimal aging conditions (Moscovitch and Winocur 1995).

Reversal learning tasks, which predominantly rely on executive functions (Lai et al. 1995; Adams et al. 2000b), provide another measure for assessing inhibitory control in aging. Discrimination reversals require subjects to inhibit prepotent responses to previously correct stimuli and to shift responses to a new stimulus-reward contingency within the same perceptual dimension. Although discrimination reversal tasks are used primarily to study animal models of aging (Tighe 1964; Freidman and Marshall 1965; Beck et al. 1966; Coutant and Warren 1966; Buchmann and Grecian 1974; Davis 1978; Bartus et al. 1979; Levine et al. 1987; Rapp 1990; Means and Holsten 1992; Milgram et al. 1994; Lai et al. 1995; Rahner-Welsch et al. 1995; Head et al. 1998; Voytko 1999; Itoh et al. 2001; Bonney and Wynne 2002), they are easily adapted for tests of inhibitory control in humans (Kendler and Kendler 1959; Kendler et al. 1960; Oscar-Berman and Zola-Morgan 1980; Freedman and OscarBerman 1989; Daum et al. 1991; Lawrence et al. 1999).

Discrimination paradigms, when applied to human populations, reveal dissociations between discrimination and reversal learning tasks. Kendler and Kendler (1959) and Kendler et al. (1960) found that young children were impaired on reversal shifts relative to nonreversal shifts. Among older adults however, reversal deficits generally correlate with severity of dementia (Oscar-Berman and ZolaMorgan 1980; Freedman and Oscar-Berman 1989; Lawrence et al. 1999). For example, Freedman and Oscar-Berman

LEARNING \& MEMORY 10:64-73 @ 2003 by Cold Spring Harbor Laboratory Press ISSN1072-0502/03 \$5.00

$$
\begin{array}{lllllllllllllll}
L & E & A & R & N & I & N & G & \mathbf{Q} & M & E & M & O & R & Y \\
\text { www.learnmem.org } & & &
\end{array}
$$


(1989) found that Alzheimer's patients had more severe reversal learning deficits than demented Parkinson's patients. In both dementing conditions, reversal deficits were manifested as perseverative responding.

In nonhuman primates, the research does not reveal a consensus. Some studies have reported robust age-related reversal learning impairments (Davis 1978; Bartus et al. 1979; Dean and Bartus 1988; Lai et al. 1995; Itoh et al. 2001; Tsuchida et al. 2002); others have not found differences (Bernstein 1961; Rapp 1990; Voytko 1993, 1999; Anderson et al. 1996; Herndon et al. 1997; Lacreuse et al. 1999). Furthermore, attempts to describe the types of errors that occur during reversal learning in aged primates provide mixed results. Although some studies indicate that reversal errors in aged primates result from perseverative responding (Jones and Mishkin 1972; Lai et al. 1995; Anderson et al. 1996; Voytko 1999), others indicate that deficits in forming stimulus-reward contingencies underlie reversal impairments (Jones and Mishkin 1972; Voytko 1999; Itoh et al. 2001).

We previously used an object discrimination learning task as part of an extensive battery of tests to measure agerelated cognitive changes in a canine model of aging, and we found that aged dogs were impaired relative to young dogs on the reversal, but not on the initial object discrimination (Milgram et al. 1994). However, a follow-up study did not find significant differences in either initial or reversal learning, but age-related differences were observed on a size discrimination task (Head et al. 1998). This latter study was limited, however, by small sample sizes (4 young dogs, 7 middle-aged dogs, and 4 old dogs), constraints on length of testing ( 50 trials), and the absence of a size reversal task to assess possible differences in inhibitory control between young and old beagle dogs. These conflicting results and the absence of any measures to assess the nature of errors in the reversal task make it difficult to draw any conclusions about

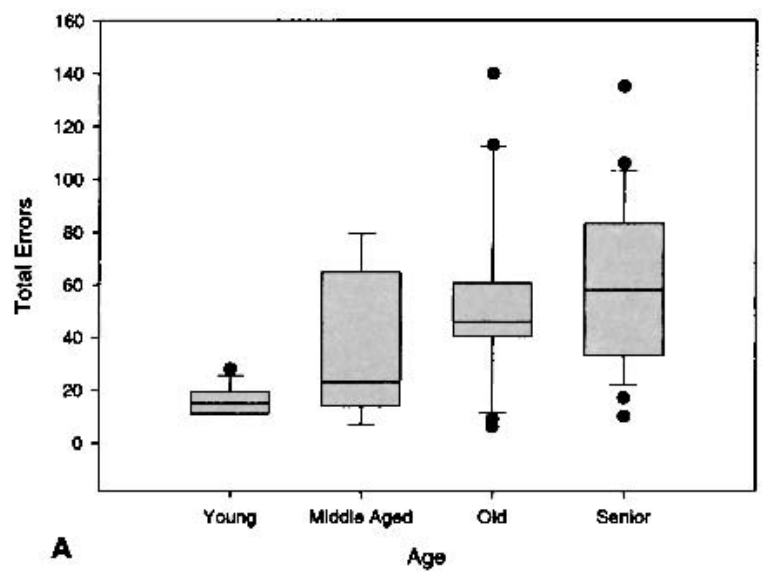

inhibitory control in aging beagle dogs. The present study reexamined the effects of age on discrimination and reversal learning, using a size discrimination task in young, middle-aged, old, and senior beagle dogs. In addition to using trials and errors to criterion as a performance measure, we also examined the types of errors made during reversal learning to provide a more accurate assessment of which processes (i.e., inhibitory vs. stimulus-reward acquisition) are impaired in reversal learning.

\section{RESULTS}

\section{Contributions of Object Preference, Test Site, and Housing Condition}

There were no significant differences between test sites, object preference, or housing conditions on either trials or errors to criterion during the original learning and reversal tasks and as such, these results are not reported.

\section{Initial Size Learning}

Analysis of size learning revealed a significant effect of age on both errors $[H(3)=13.79, P=.003]$ and trials to criterion $[H(3)=14.80, P=.002]$. Pairwise comparisons of errors and trials to criterion, shown in Figure 1, indicate that old and senior dogs made significantly more errors $(U=17.0, P=.003 ; U=15.5, P=.0001)$ and required more trials $(U=16.0, P=.002 ; U=9.0, P=.0001)$ than the young dogs. Although errors increased progressively with age, none of the other group differences were significant $(P>.05)$

Backward learning curves are shown in Figure 2. The curves indicate that the old and senior dogs showed slow but progressive improvement over many sessions. In contrast, the young and middle-aged dogs were more likely to show rapid insight-like learning, requiring fewer total sessions to reach criterion. Age significantly influenced both

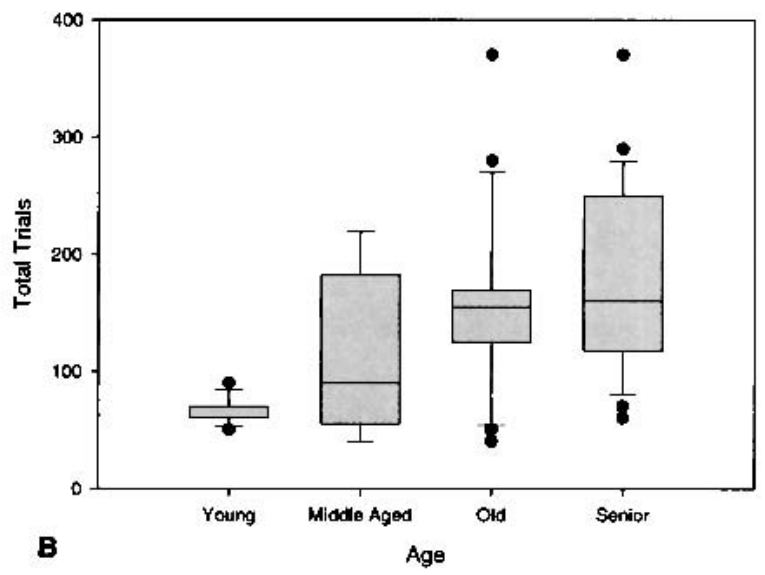

Figure 1 Box plots of total errors $(A)$ and trials $(B)$ to criterion for young, middle-aged, old, and senior dogs on initial size discrimination learning. Median errors and trials to criterion for each group are indicated by a single line inside the box plot. Longer box plots and whiskers indicate greater variability and skewness respectively, within a group. Individual data points indicate outliers within a group.

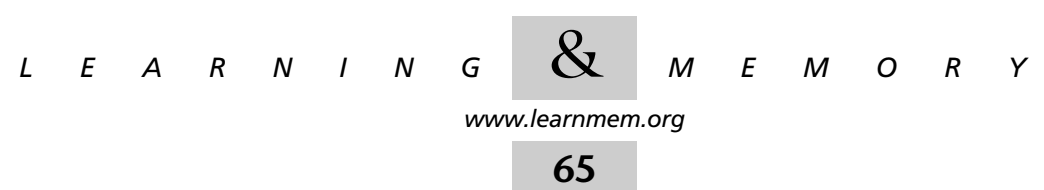



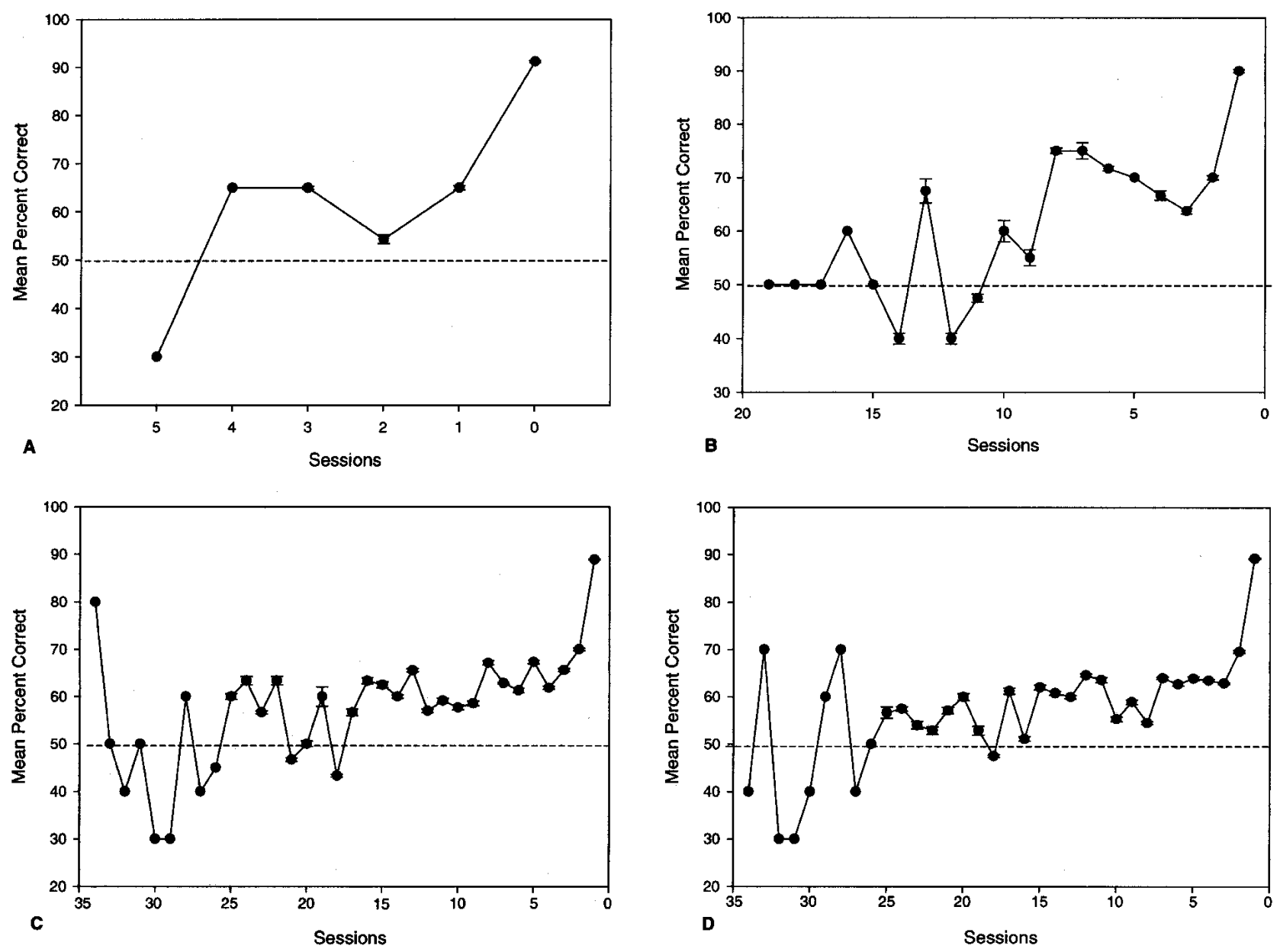

Figure 2 Backward learning curves for the acquisition of the size discrimination task by young $(A)$, middle-aged $(B)$, old $(C)$, and senior $(D)$ dogs. Data points represent mean percent correct scores ( \pm standard error of the mean) and are plotted backwards from the test session in which criterion is reached (i.e., 0 ).

the total number of sessions spent at or below $50 \%$ correct $[H(3)=11.26, P=.010]$, as well as the total number of sessions above $50 \%$ correct $[H(3)=15.88, P=.001]$. Betweengroup comparisons indicated that compared to the young dogs, old $(U=26.5, P=.010)$ and senior $(U=26.0$, $P=.002)$ dogs spent significantly more sessions performing at or below chance when learning the size discrimination task. Similarly, both old $(U=14.0, P=.001)$ and senior ( $U=7.0, P=.0001)$ dogs required more sessions responding above chance to satisfy criterion measures and complete the initial size task. No other comparisons were significant.

\section{Size Reversal Learning}

Wilcoxon signed ranks tests were performed to compare rates of learning on size and reversal acquisition (Fig. 3). Total errors to criterion were significantly higher on the reversal task compared to the size task for young $(P=.012)$, old $(P=.006)$, and senior dogs $(P=.0001)$ but not middle- aged dogs $(P=.893)$. Trials to criterion were also significantly higher on the reversal task for young $(P=.012)$, old $(P=.048)$, and senior dogs $(P=.002)$ but not middle-aged dogs $(P=.686)$. Analysis of size-reversal learning performance (Fig. 4) revealed a significant effect of age on both errors $[H(3)=18.56, P=.0001]$ and trials $[H(3)=19.51$, $P=.0001]$ to complete criterion. Separate pairwise comparisons revealed several significant differences between the aged groups. First, compared to young dogs, old dogs made significantly more errors $(U=34.50, P=.050)$ to reach criterion. The number of trials required to reach criterion in the old group however, did not significantly differ from that of the young dogs $(U=37.50, P=.074)$. Second, senior dogs made more errors $(U=11.50, P=.0001)$ and required more trials to achieve criterion $(U=7.50$, $P=.0001)$ compared to the young dogs. Finally, in contrast to the original learning task, senior dogs differed from middle-aged dogs on the reversal task, with senior dogs

$$
\begin{array}{lllllllllllllll} 
& E & A & R & N & I & N & G & \& & M & E & M & O & R & Y \\
\text { www.learnmem.org } & & &
\end{array}
$$




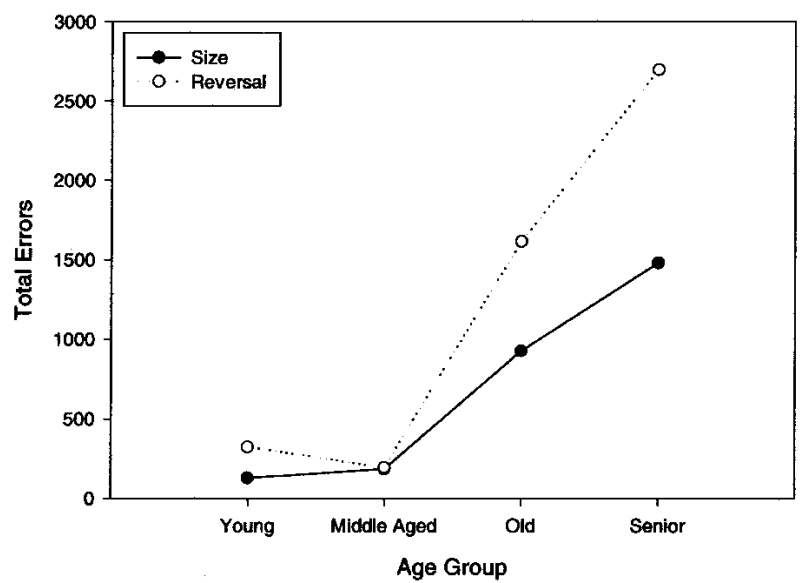

A

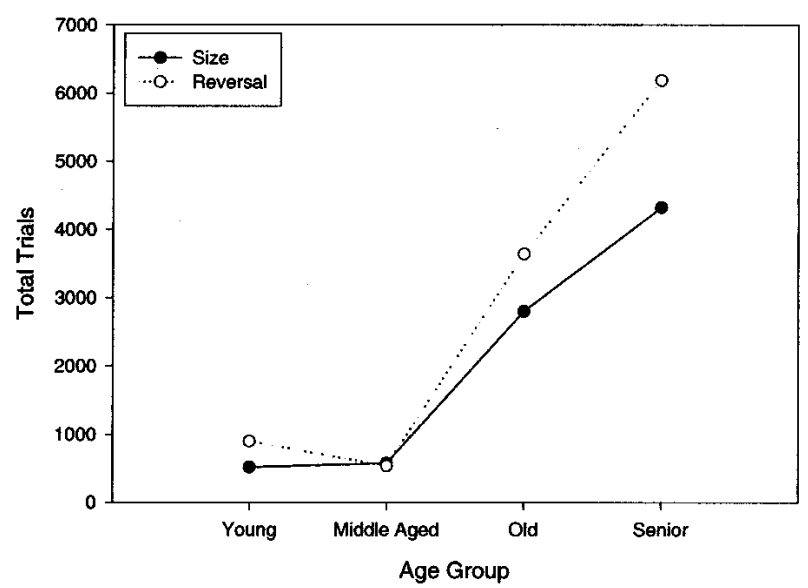

B

Figure 3 Rate of learning comparisons for total errors $(A)$ and trials $(B)$ to criterion on size and size reversal discrimination tasks. Young, old, and senior dogs took longer to learn the reversal task compared to the original size-learning condition.

making more errors $(U=3.50, P=.001)$ and requiring more trials $(U=3.50, P=.001)$ to achieve criterion on the reversal task. No other between-group comparisons were significant.

Analysis of the stages of reversal learning (Fig. 5) revealed a significant effect of age on Stage $\mathrm{I}[H(3)=7.58$, $P=.05]$, Stage II $[H(3)=19.49, P=.0001]$, and Stage III $[H(3)=8.43, P=.038]$. Group comparisons for each learning stage indicated that compared to young dogs, senior dogs spent significantly more sessions at Stage I $(U=40.00$, $P=.014)$. No other groups significantly differed in the number of Stage I errors made. Senior dogs also differed from young $(U=12.50, \quad P=.0001)$, middle aged $(U=6.00$, $P=.002)$, and old $(U=139.00, P=.05)$ dogs in the number of sessions spent at Stage II. Similarly, old dogs spent more sessions at Stage II relative to young $\operatorname{dogs}(U=33.00, P$

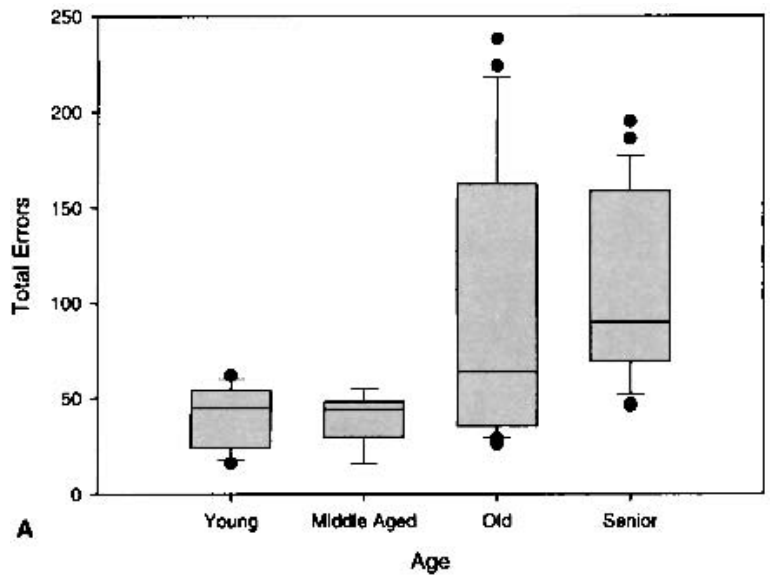

$=.030$ ). Senior dogs also spent more sessions at Stage III learning compared to young $(U=46.50, P=.029)$ and middle-aged dogs $(U=20.00, P=.019)$. Senior dogs, however, did not differ in the number of sessions spent in Stage III ( $U=147.00, P=.078)$ compared to old dogs.

\section{DISCUSSION}

The primary goal of the present study was to examine executive dysfunction in aged dogs using a size-reversal learning task to examine inhibitory control. Old and young dogs were first trained on a size-discrimination learning task. After acquiring the task, the reward contingencies were reversed and the animals were trained on a reversal learning task, which is sensitive to executive function deficits (Lai et al. 1995; Adams et al. 2000b).

Figure 4 Box plots of total errors $(A)$ and trials $(B)$ to criterion for young, middle-aged, old, and senior dogs on size-reversal discrimination learning. Median errors and trials to criterion for each group are indicated by a single line inside the box plot. Longer box plots and whiskers indicate greater variability and skewness respectively, within a group. Individual data points indicate outliers within a group.

$$
\begin{array}{lllllllllllllll}
L & E & A & R & N & I & N & G & \mathcal{Q} & M & E & M & O & R & Y \\
\text { www.learnmem.org } & & &
\end{array}
$$




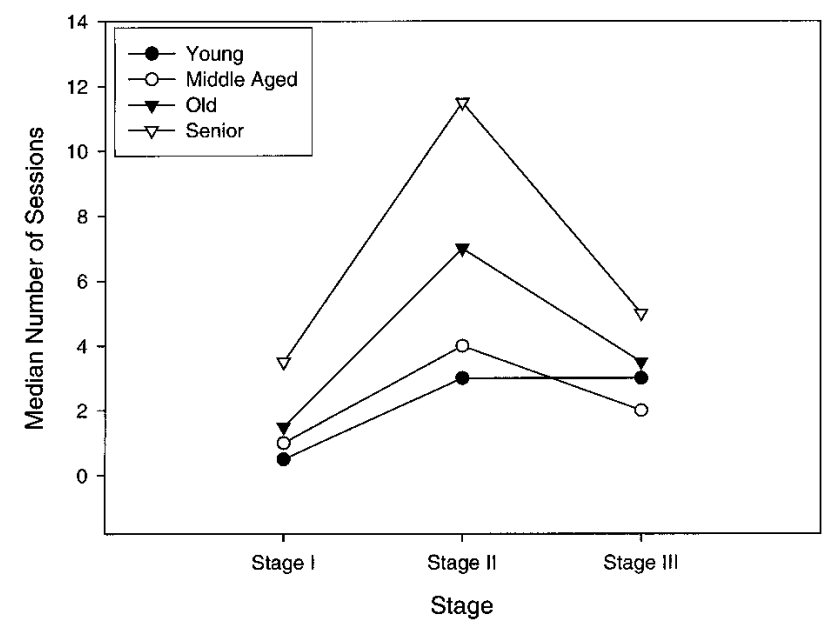

Figure 5 Median number of sessions spent at stage I, II, and III during reversal learning by young, middle-aged, old, and senior beagle dogs.

\section{Size Learning}

The size-discrimination task requires that the subjects learn to discriminate between two objects that are identical in all respects but one: the height of the objects. Object discrimination learning is generally insensitive to age in both primates (Bartus et al. 1979; Arnsten and Goldman-Rakic 1985; Dean and Bartus 1988; Walker et al. 1988; Rapp 1990; Lai et al. 1995; Anderson et al. 1996; Voytko 1999; Tsuchida et al. 2002) and dogs (Milgram et al. 1994; Head et al. 1998). In the present experiment however, we did observe age-related impairments in size-discrimination learning, particularly in the old and senior dogs. According to Mackintosh (1974) and Sutherland and Mackintosh (1971), successful acquisition of a visual discrimination consists of two stages: attending to the relevant stimulus dimensions, and associative learning of the correct stimulus-reward contingencies. Results from the backward learning curve analysis suggest that both stages of discrimination learning were impaired in the old and senior dogs. Compared to young and middleaged dogs, both groups of aged dogs spent more sessions responding at or below chance. This protracted period of responding below chance may reflect an impaired ability to attend to the relevant task information (i.e., size), which is a common problem among aged subjects (Hasher and Zacks 1988; Hasher et al. 1991; McDowd and Oseas-Kreger 1991; McDowd et al. 1995). Old and senior dogs also required more sessions responding above chance to reach criterion. This second period of protracted responding represents a delay in acquiring the correct stimulus-reward contingencies in the aged group (Jones and Mishkin 1972).

The delay could simply represent an age-dependent deficit in stimulus-reward learning. Alternatively, two additional factors could account for the impaired size learning: (1) the restricted number of discernible stimulus attributes (only size), and (2) task complexity. The suggestion that learning might be slowed by reducing the number of stimulus attributes is supported by the Thomas and Frost (1983) finding that squirrel monkeys learn oddity discriminations more rapidly with two relevant stimulus dimensions compared to one stimulus dimension. Similarly, both old and young dogs perform well on object discrimination tasks in which the discriminanda differ in a number of perceptual attributes including color, shape, size, and form (Head et al. 1998). In both the Head et al. (1998) and the present study, however, aged dogs were impaired relative to young dogs when the only discernible feature between discriminanda was size.

Differential task complexity is another factor that could contribute to age differences in size discrimination. Both Rapp (1990) and Voytko (1999) reported that complex pattern discriminations are more sensitive to age-related changes in discrimination learning than simple object-discrimination tasks. Similarly, Strong et al. (1968) consistently found that across several species, height is more difficult than color or form to discriminate. One possible reason why a size-discrimination task may be particularly difficult is because the objects differ in only a single dimension which can be solved using relative, rather than absolute cues. Compared to an object-discrimination task in which the properties associated with reward are inherent in the object (e.g., the color blue or the circular nature of an object), size is a relative attribute that may change from trial to trial. Thus, a small object that is correct on one trial may be incorrect on a subsequent trial if it is paired with a smaller (and now correct) object. Success on a size-discrimination task would therefore necessitate the ability to both perceive differences in size and understand the conceptual aspect of size when identifying the relevant reward-based stimulus. The finding that old dogs are impaired on size discriminations and not object discriminations (Head et al. 1998) suggests that conceptual deficits may underlie size-discrimination learning impairments. Support for this hypothesis was recently obtained in a study in which old and young dogs were presented with several sets of object arrays (i.e., blocks, balls, and bottles) that differed only with respect to size. Compared to young dogs, old dogs were impaired at acquiring both large and small concepts and were unable to transfer learning to novel sets of different sized objects (Tapp et al. 2001).

\section{Reversal Learning}

The primary goal of this study was to examine the nature of reversal learning in aging, in an attempt to further our understanding of executive function deficits. We found that reversal learning generally occurred more slowly than the original size learning. This slower rate of learning was expected, given the likelihood that acquisition depends on the ability to shift cognitive set from a previous to a new stimulus-reward contingency (Voytko 1999). Although young

$$
\begin{array}{lllllllllllllll} 
& E & A & R & N & I & N & G & \mathcal{Q} & M & E & M & O & R & Y \\
\text { www.learnmem.org } & &
\end{array}
$$


dogs exhibited slower reversal learning relative to size learning, aged dogs in general were far more impaired at the reversal task. The present results are consistent with studies that report age-related differences in reversal learning (Davis 1978; Bartus et al. 1979; Dean and Bartus 1988; Milgram et al. 1994; Lai et al. 1995; Itoh et al. 2001; Tsuchida et al. 2002) but are at odds with other studies that fail to find an effect of age on reversal learning (Bernstein 1961; Levine et al. 1987; Rapp 1990; Voytko 1993, 1999; Lai et al. 1995; Anderson et al. 1996; Herndon et al. 1997; Head et al. 1998; Lacreuse et al. 1999). These discrepant findings may arise because reversal learning deficits may only become apparent in advanced stages of aging (Voytko 1999; Itoh et al. 2001). In most primate studies, the aged subjects do not represent the oldest possible subjects (Voytko 1999). Thus, failure to detect age-related reversal learning differences may reflect the use of a restricted range of old subjects. Possibly a more important reason for the diversity in reversal learning data is individual differences associated with aging. Our studies of cognitive aging in beagle dogs have indicated that individual variability in cognitive performance increases with age such that at least three distinct populations of aged dogs can be identified: those that are severely cognitively impaired, those that show mild impairments, and those that perform at levels similar to those of young dogs (Milgram et al. 1994; Head et al. 1995; Cummings et al. 1996a,b; Adams et al. 2000a; Head et al. 2001; Siwak et al. 2002). To account for this age-associated increase in cognitive variability, the present study separated aged dogs into two distinct groups based on chronological age. The purpose of this strategy was not to eliminate within-group variability, but rather to assess age differences within the cognitive mechanisms involved in reversal learning over a broader age range than what is typically studied.

Although old and senior dogs did not differ in the number of trials or errors to criterion on the reversal task, results from the stage-learning analysis clearly indicate that the senior dogs represent a distinct group of aged animals. Senior dogs made more Stage I errors than the other groups. This pattern of errors is indicative of perseverative behaviors which occur when an animal is unable to inhibit prepotent responses to a previously rewarded stimulus following a change in the stimulus-reward contingencies (Settlage et al. 1948; Mishkin 1964; Iversen and Mishkin 1970; Jones and Mishkin 1972; Lai et al. 1995; Voytko 1999). In contrast, old dogs spent more total sessions in Stage II and III learning, suggesting that the nature of reversal impairments in the old dogs represents a deficit in learning new stimulus-reward contingencies (Jones and Mishkin 1972). The increased Stage II and III errors are also consistent with the protracted period of responding above chance during the acquisition of the size-discrimination task in the aged dogs, suggesting that the ability to form a new stimulus-reward contingency is in fact impaired in the old dogs. Therefore, despite simi- larities in reversal learning, the stage-learning analysis suggests that separate mechanisms are responsible for reversal learning deficits in the old and senior dogs.

\section{Functional and Anatomical Implications}

The present study is part of an ongoing research program to examine the relationship between executive processes and frontal lobe structure in a canine model of aging. Inhibitory control mechanisms are a critical component of executive functions that contribute to accurate performance (Roberts et al. 1998). Lesion and imaging studies indicate that the inferior prefrontal cortex plays a critical role in inhibition of perseverative behaviors (Mishkin 1964; Butter 1969; McEnaney and Butter 1969; Iversen and Mishkin 1970; Jones and Mishkin 1972), inhibition of distracting sensory information (Chao and Knight 1997), and inhibition of inappropriate prepotent response tendencies in motor (Sasaki and Gemba 1986; Kawashima et al. 1996; Konishi et al. 1999; Liddle et al. 2001; Menon et al. 2001) and cognitive (Vendrell et al. 1995; Rebai et al. 1997; Jonides et al. 1998; Garavan et al. 1999; West and Alain 2000; Nielson et al. 2002) processes. In the present study, failure to inhibit perseverative behaviors was characteristic of the oldest dogs (i.e., seniors) in the aged group. According to Kreiner (1968), the orbital gyrus and paraorbital gyrus in the canine are homologous to the inferior prefrontal gyrus in the primate. Thus, it is possible that the inhibitory deficits in the senior dogs were due to age-related changes in these prefrontal areas that are typically involved in inhibitory control.

The stimulus-reward deficits (i.e., stage II errors) observed in both old and senior dogs may reflect age-related changes in the subproreal gyrus, an area that is homologous to the primate medial orbitofrontal cortex (Kreiner 1968) and believed to control stimulus-reward learning (Dias et al. 1997; Rolls 1998, 2000; Wallis et al. 2001). Together, the results suggest that the prefrontal cortex in the beagle dog and the subregions involved in stimulus-reward acquisition and inhibitory control may be particularly vulnerable to the effects of aging. Evidence supporting this hypothesis was recently found in a volumetric study assessing changes in regional brain size using magnetic imaging techniques in the beagle dog. Compared to young and middle-aged dogs, frontal lobe size was significantly reduced in senior and old dogs (Tapp et al. 2002).

Although the present results indicate that executive function deficits may underlie age-related reversal learning impairments, clearly, further studies are required to fully characterize executive dysfunction in the aging dog. Additional studies are currently underway to examine a range of executive processes and how age-related changes to these higher-order cognitive processes correlate with volumetric changes in subregions of the frontal cortex in the aging beagle dog.

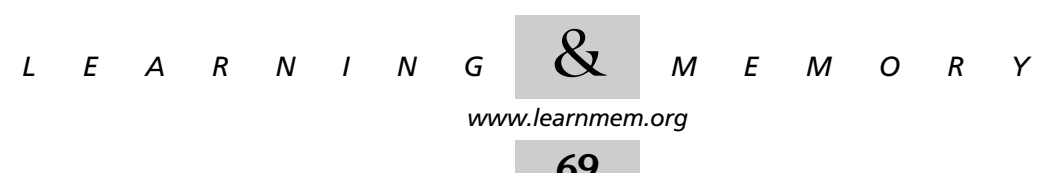




\section{MATERIALS AND METHODS}

\section{Subjects}

The subjects were beagle dogs (Canis familiaris), divided into four age groups: young, middle-aged, old, and senior. There were eight dogs in the young group (2.91-3.73 years old; $M=3.40$, $S D=0.28)$, five in the middle-aged group $(4.05-5.50$ years old; $M=4.81, S D=0.66), 17$ in the old group (8.61-10.94 years old; $M=9.92, S D=0.87)$, and 25 in the senior group (11.10-13.81 years old; $M=11.95, S D=0.71$ ). Dogs were obtained from two different sources (Lovelace Respiratory Research Institute, (LRRI), Albuquerque, New Mexico; LBL Kennels, Indianapolis, Indiana) and housed at three different locations (LRRI; Division of Comparative Medicine (DCM), University of Toronto, Toronto, Canada; Scarborough College, University of Toronto). All dogs at DCM were individually housed (eight senior, 11 old, two middle-aged, and three young dogs). Of the dogs at LRRI, 12 were individually housed (eight senior, four old) and 11 were group-housed (nine senior, two old). All seven dogs at the Scarborough facility were group-housed (four young, three middle-aged). Fresh water was provided daily ad libitum, and subjects were fed approximately 300 $\mathrm{g}$ of Purina Dog Chow in the afternoon following cognitive testing. Animals were visually examined daily by trained veterinary animal personnel and research staff. Comprehensive clinical examinations for respiratory, urogenital, musculoskeletal, digestive, visual, and auditory functioning were performed biannually. Neurological tests to assess motor and sensory deficits were conducted annually. All dogs were in excellent health at the time of the study, and all procedures were conducted in accordance with Canadian Council on Animal Care guidelines.

\section{Apparatus}

Testing was conducted in a $0.609 \mathrm{~m} \times 1.15 \mathrm{~m} \times 1.08 \mathrm{~m}$ wooden canine-adaptation of the Wisconsin General Test Apparatus as described (Milgram et al. 1994). The testing chamber was equipped with a sliding Plexiglas food tray with three food wells, two lateral and one medial. The front of the box consisted of adjustable vertical stainless steel bars. The experimenter was separated visually from the dog by a screen with a one-way mirror and a hinged door on the bottom. Cognitive testing was conducted in darkness except for a light with a 60 -watt bulb attached to the front of the box. The hinged door was opened for the presentation and removal of the food tray. Approximately $1 \mathrm{~cm}^{3}$ of wet $\operatorname{dog}$ food (Hill's Prescription Diet p/d; Hill's Pet Nutrition) was used as the food reward for each trial. Only the two lateral wells were used for both tasks described in the present study.

Data acquisition was performed using a dedicated computer program developed in the ASYST (ASYST Software Technologies) programming language. The program controlled timing, randomization procedures, indicated the location of the reward, and was used to store and backup all data files.

\section{Behavioral Tasks}

\section{Pretraining}

Dogs at all three research locations received a standard four-phase pretraining protocol (Milgram et al. 1994). This procedure included a phase to expose the dogs to the test apparatus, a phase to teach the dogs that a food reward was always present in one of the food wells (reward approach learning), a phase to manually shape dogs to displace objects, and a final phase to teach dogs to visually locate and approach objects on the sliding tray (object approach learn- ing). All dogs completed each of these four phases before further testing procedures were conducted. Dogs at all three facilities were also tested on a number of other recognition tasks including an object discrimination and reversal task before being tested on the size discrimination and reversal task.

\section{Size Discrimination Learning}

Stimuli for this task consisted of three wooden blocks $(8.8 \times 4 \times 2$ $\mathrm{cm})$. Two blocks were glued together with epoxy glue to create a single large stimulus. The third block served as the small stimulus. Both objects were identical in color and material, and differed only in apparent size. A small hole ( $3 \mathrm{~cm}$ in diameter, $1 \mathrm{~cm}$ deep) was drilled into the bottom of the stimuli so that food could be placed under the incorrect stimulus, hidden from view, to control for odor cues during the task.

The first test session of the size learning task was used to establish size preferences. The wooden blocks were placed over the lateral wells both containing the food reward. Locations of each object were randomized across trials with the proviso that each object would not occupy either lateral well more than five times per session. Dogs were required to displace the block to retrieve the reward. A total of 10 trials with both objects baited and presented randomly five times on the left or right side of the tray were administered during the preference test. The block most frequently selected by the animal (i.e., six or more times) was deemed the preferred object. If no object preference was established, one of the two blocks was randomly assigned as preferred. Testing began the following day with either the animal's nonpreferred $(n=30 ; 14$ senior, 10 old, two middle-aged, four young dogs) or preferred ( $n=25 ; 11$ senior, seven old, three middle aged, four young dogs) object as the correct stimulus.

All dogs received 10 daily trials, 7 d per wk with a $30-\mathrm{sec}$ interval between trials. Each trial began with the placement of food reward in one of the lateral wells and the corresponding positive block (i.e., large or small block) placed over the food well. The remaining lateral well was unbaited, and the incorrect block was placed over the food well with food in the bottom of the block to control for odor. After a computer-emitted tone signaled the start of the trial, the hinged door was raised, and the sliding tray extended one-third of the way towards the dog. A 3-sec inspection interval timed by the computer allowed the dog to examine both objects before the tray was fully extended for the animal to make a response. A correct response was recorded when a dog approached and displaced the positive block. An error was committed if a dog approached and displaced the negative block. One correction per test session on the first error was permitted, and all subsequent errors resulted in the immediate withdrawal of the tray and termination of the trial.

All dogs were required to complete a two-stage criterion procedure to pass the size-discrimination learning task. To satisfy the first criterion stage, a score of $9 / 10$ or $10 / 10$ on a single test day or $8 / 10$ on two consecutive test days was required. After completing the stage one criterion, a subsequent score of $70 \%$ correct or better over three consecutive test days was required to pass criterion. If criterion measures were not met within $40 \mathrm{~d}$, testing was suspended and reversal procedures were not performed.

\section{Size-Discrimination Reversal Learning}

After the dogs reached criterion measures in the size-discrimination learning task, the reward contingencies of the positive and negative block were reversed and the animals were tested on a size reversal task. Testing on this task began the first day after the size learning

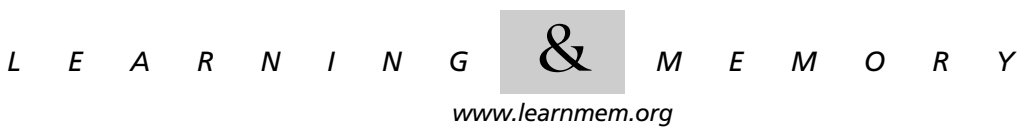


procedures. In all other respects, testing procedures for the reversal task were identical to those used with the size discrimination learning.

\section{Data Analysis}

Total numbers of errors and trials to complete both the size discrimination and size reversal tasks up to and including criterion days were calculated for each dog. Given the relatively small sample sizes in two of the groups (i.e., $n=5$ and $n=8$ for middleaged and young dogs, respectively) and the lack of normal distributions for size and reversal learning errors and trials indicated by the Shapiro-Wilk test of normality, a Kruskal-Wallis one-way ANOVA was used to examine the effects of age on errors and trials to criterion for the size and reversal learning conditions. Post-hoc analyses were performed using the Mann-Whitney U test. Wilcoxon signed ranks tests were also performed to compare the rate of learning on the size and reversal task within each group of dogs.

Additional analyses were performed to determine whether age selectively affected particular stages of acquisition or reversal learning. For acquisition of the initial size learning task, groupaveraged backward learning curves were generated according to the method described by Hayes (1953). Unlike conventional learning curves which compare group means, the backward learning curve allows for comparisons among groups of subjects that require different amounts of training before criterion measures are achieved. Using this method, percent correct scores were calculated for each session preceding the attainment of criterion for each dog in the study. Statistical comparisons among the four age groups using the Mann-Whitney $U$ test were performed on the number of sessions at or below $50 \%$ correct and the number of sessions above $50 \%$ correct.

For reversal learning, a stage-learning analysis was performed using the methods described by Jones and Mishkin (1972) and Duel, Mishkin, and Semmes (1971) to categorize the errors into one of three stages and to provide an index of perseveration (i.e., the inability to inhibit responses to a previously reinforced stimulus). We defined stage $I$ as the occurrence of seven or more errors within a single session of 10 trials. This provided a measure of perseverative responding. Stage II represented chance performance with four to six errors in a block of 10 trials. Stage III was characterized as an above chance level of performance with zero to three errors occurring in a single test session.

Kruskal-Wallis one-way analysis of variance procedures were used to examine the effects of age on each stage of learning during the reversal task. Pairwise comparisons were performed with the Mann-Whitney procedure for nonparametric data. All analyses were performed using SPSS for Windows (version 10.0.5).

The publication costs of this article were defrayed in part by payment of page charges. This article must therefore be hereby marked "advertisement" in accordance with 18 USC section 1734 solely to indicate this fact.

\section{REFERENCES}

Adams, B., Chan, A., Callahan, H., Siwak, C., Tapp, D., Ikeda-Douglas, C., Atkinson, P., Head, E., Cotman, C.W., and Milgram, N.W. 2000a. Use of a delayed nonmatching to position task to model age-dependent cognitive decline in the dog. Behav. Brain Res. 108:47-56.

Adams, B., Chan, A., Callahan, H., and Milgram, N.W. 2000b. The canine as a model of human cognitive aging: Recent developments. Prog. Neuropsychopharmacol. Biol. Psychiatry 24:675-692.

Anderson, J.R., de Monte, M., and Kempf, J. 1996. Discrimination learning and multiple reversals in young adult and older monkeys (Macaca arctoides). Q. J. Exp. Psychol. B. 49:193-200.

Arbuckle, T.Y. and Gold, D.P. 1993. Aging, inhibition, and verbosity. $J$. Gerontol. 48:225-232.

Arnsten, A.F.T. and Goldman-Rakic, P.S. 1985. Catecholamines and cognitive decline in aged nonhuman primates. Ann. NY Acad. Sci. 444:218-234

Bartus, R.T., Dean III, R.L., and Flemming, D.L. 1979. Aging in the rhesus monkey: Effects on visual discrimination learning and reversal learning. J. Gerontol. 34:209-219.

Beck, C.H., Warren, J.M., and Sterner, R. 1966. Overtraining and reversal learning by cats and rhesus monkeys. J. Comp. Physiol. Psychol. 62:332-335.

Bernstein, L.S. 1961. Response variability and rigidity in the adult chimpanzee. J. Gerontol. 16:381-386.

Bonney, K.R. and Wynne, C.D.L. 2002. Quokkas (Setonix brachyurus) demonstrate tactile discrimination learning and serial reversal learning. J. Comp. Psychol. 116:51-54.

Buchmann, O.L.K. and Grecian, E.A. 1974. Discrimination-reversal learning in the marsupial Isoodon obesulus (Marsupialia, Peramelidae). Anim. Behav. 22:975-981.

Butter, C.M. 1969. Perseveration in extinction and in discrimination reversal tasks following selective frontal ablations in Macaca mulatta. Physiol. Behav. 4:163-171.

Chao, L.L. and Knight, R.T. 1997. Prefrontal deficits in attention and inhibitory control with aging. Cereb. Cortex. 7:63-69.

Connelly, S.L. and Hasher, L. 1993. Aging and the inhibition of spatial location. J. Exp. Psychol. Hum. Percept. Perform. 19:1238-1250.

Connelly, S.L., Hasher, L., and Zacks, R.T. 1991. Age and reading: The impact of distraction. Psychol. Aging 6:533-541.

Coutant, L.W. and Warren, J.M. 1966. Reversal and nonreversal shifts by cats and rhesus monkeys. J. Comp. Physiol. Psychol. 61:484-487.

Cummings, B.J., Head, E., Afagh, A.J., Milgram, N.W., and Cotman, C.W. 1996a. $\beta$ amyloid accumulation correlates with cognitive dysfunction in the aged canine. Neurobiol. Learn. Mem. 66:11-23.

Cummings, B.J., Head, E., Ruehl, W.W., Milgram, N.W., and Cotman, C.W 1996b. The canine as an animal model of human aging and dementia. Neurobiol. Aging 17:259-268.

Daum, I., Schugens, M.M., Channon, S., Polkey, C.E., and Gray, J.A. 1991. T-maze discrimination and reversal learning after unilateral temporal or frontal lobe lesions in man. Cortex 27:613-622.

Davis, R.T. 1978. Old monkey behavior. Exp. Gerontol. 13:237-250.

Dean R.L. and Bartus, R.T. 1988. Behavioral models of aging in nonhuman primates. In Handbook of psychopharmacology (eds. L.L. Iverson, S.D. Iverson, and S.H. Snyder), Vol. 20, pp. 325-392. Plenum, NY.

Dias, R., Robbins, T.W., and Roberts, A.C. 1997. Dissociable forms of inhibitory control within prefrontal cortex with an analogue of the Wisconsin card sort test: Restriction to novel situations and independence from on-line processing. J. Neurosci. 17:9285-9297.

Duel, R.K., Mishkin, M., and Semmes, J. 1971. Interaction between the hemispheres in unimanual somesthetic learning. Exp. Neurol. 30:123-138.

Dywan, J. and Murphy, W.E. 1996. Aging and inhibitory control in text comprehension. Psychol. Aging 11:199-206.

Eisenstein, E.M., Eisenstein, D., Bonheim, P., and Welch, E.A. 1990. Habituation of the galvanic skin response in adult males as a function of age. Physiol. Behav. 48:169-173.

Faust, M.E., Balota, D.A., Duchek, J.M., Bernsbacher, M.A., and Smith, S 1997. Inhibitory control during sentence completion in individuals with dementia of the Alzheimer's type. Brain Lang. 57:225-253.

Freedman, M. and Oscar-Berman, M. 1989. Spatial and visual deficits in Alzheimer's and Parkinson's disease. Brain Cogn. 11:114-126.

Freidman, H. and Marshall, D.A. 1965. Position reversal training in the Virginia opossum: Evidence for the acquisition of a learning set. $Q . J$. Exp. Psychol. B. 17:250-254

Garavan, H., Ross, T.J., and Stein, E.A. 1999. Right hemispheric dominance of inhibitory control: An event-related functional MRI study. Proc. Natl. Acad. Sci. 96:8301-8306.

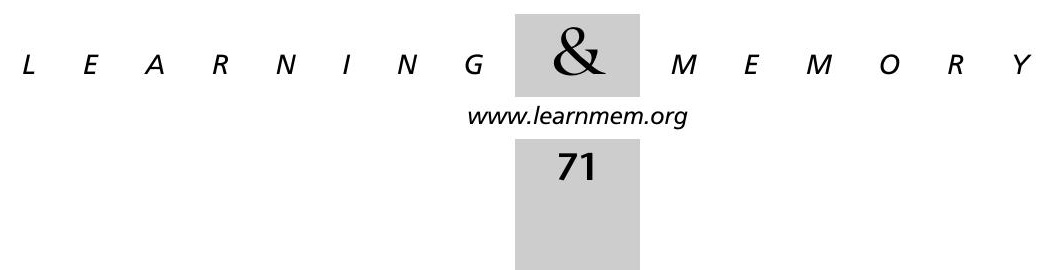


Hamm, V. and Hasher, L. 1992. Aged and the availability of inferences Psychol. Aging 7:56-64.

Hartley, A.A. 1993. Evidence for the selective preservation of spatial attention in old age. Psychol. Aging 8:371-379.

Hartman, M. and Hasher, L. 1991. Aging and suppression: Memory for previously relevant information. Psychol. Aging 6:587-594.

Hasher, L. and Zacks, R.T. 1988. Working memory, comprehension, and aging: A review and a new view. In The Psychology of Learning and Motivation (ed. G.H. Bower), pp 193-225. Academic Press, San Diego, CA.

Hasher, L., Stoltzfus, E.R., Zacks, R.T., and Rympa, B. 1991. Age and inhibition. J. Exp. Psychol. Learn. Mem. Cogn. 17:163-169.

Hayes, K.J. 1953. The backward learning curve: A method for the study of learning. Psychol. Rev. 60:269-275.

Head, E., Mehta, R., Hartley, J., Kameka, M., Cummings, B.J., Cotman, C.W., Ruehl, W.W., and Milgram, N.W. 1995. Spatial learning and memory as a function of age in the dog. Behav. Neurosci. 109:851-858.

Head, E., Callahan, H., Muggenburg, B.A., Cotman, C.W., and Milgram, N.W. 1998. Visual discrimination learning ability and $\beta$-amyloid accumulation in the dog. Neurobiol. Aging 19:415-525.

Head, E., Milgram, N.W., and Cotman, C.W. 2001. Neurobiological models of aging in the dog and other vertebrate species. In Functional neurobiology of aging (eds. P.R. Hof and C.V. Mobbs), pp. 457-468. Academic Press, San Diego, CA

Herndon, J.G., Moss, M.B., Rosene, D.L., and Killiany, R.J. 1997. Patterns of cognitive decline in aged rhesus monkeys. Behav. Brain Res. 87:25-34.

Itoh, K., Izumi, A., and Kojima, S. 2001. Object discrimination learning in aged monkeys. Behav. Neurosci. 115:259-270.

Iversen, S.D. and Mishkin, M. 1970. Perseverative interference in monkeys following selective lesions of the inferior prefrontal convexity. Exp. Brain Res. 11:376-386.

Jones, B. and Mishkin, M. 1972. Limbic lesions and the problem of stimulus reinforcement associations. Exp. Neurol. 36:362-377.

Jonides, J., Smith, E.E., Marsheutz, C., Koeppe, R.A., and Reuter-Lorenz, P.A. 1998. Inhibition in verbal working memory revealed by brain activation. Proc. Natl. Acad. Sci. 95:8410-8413.

Kane, M.J., Hasher, L., Stoltzfus, E.R., Zacks, R.T., and Connelly, S.L. 1994. Inhibitory attentional mechanisms in aging. Psychol. Aging 9:103-112.

Kawashima, R., Satoh, K., Itoh, H., Ono, S., Furumoto, S., Gotoh, R., Koyama, M., Yoshioka, S., Takahashi, T., Takahashi, K., et al. 1996. Functional anatomy of go/no-go discrimination and response selection-a PET study in man. Brain Res. 728:79-89.

Kendler, T. and Kendler, H.K. 1959. Reversal and nonreversal shifts in kindergarten children. J. Comp. Physiol. Psychol. 58:56-60.

Kendler, T.S., Kendler, H.K., and Wells, D. 1960. Reversal and nonreversa shifts in nursery school children. J. Comp. Physiol. Psychol. 53:83-88.

Konishi, S., Nakajima, K., Uchida, I., Kikyo, H., Kameyama, M., and Miyashita, Y. 1999. Common inhibitory mechanism in human inferior prefrontal cortex revealed by event-related functional MRI. Brain 122:981-991.

Kreiner, J. 1968. Homologies of the fissural and gyral pattern of the hemispheres of the dog and monkey. Acta. Anat. 70:137-167.

Lacreuse, A., Herndon, J.G., Killiany, R.J., Rosene, D.L., and Moss, M.B. 1999. Spatial cognition in rhesus monkeys: Male superiority declines with age. Horm. Behav. 36:70-76.

Lai, Z.C., Moss, M.B., Killany, R.J., Rosene, D.L., and Herndon, J.G. 1995 Executive dysfunction in the aged monkey: Spatial and object reversal learning. Neurobiol. Aging 16:947-954.

Lawrence, A.D., Sahakian, B.J., Rogers, R.D., Hodges, J.R., and Robbins, T.W. 1999. Discrimination, reversal, and shift learning in Huntington's disease: Mechanisms of impaired response selection. Neuropsychologia 37:1359-1374

Levine, M.S., Lloyd, R.L., Fisher, R.S., Hull, C.D., and Buchwald, N.A. 1987. Sensory motor and cognitive alterations in aged cats. Neurobiol. Aging 8:253-263.
Liddle, P.F., Kiehl, K.A., and Smith. A.M. 2001. Event-related fMRI study of response inhibition. Hum. Brain Mapp. 12:100-109.

Mackintosh, N.J. 1974. Discrimination learning. In The Psychology of animal learning (ed. N.J. Mackintosh), pp. 543-619. Academic Press, NY.

McDowd, J.M. and Filion, D.L. 1992. Aging, selective attention, and inhibitory processes: A psychophysiological approach. Psychol. Aging 7:65-71.

McDowd, J.M. and Filion, D.L. 1995. Aging and negative priming in a location suppression task: The long and short of it. Psychol. Aging 10:34-47.

McDowd, J.M. and Oseas-Kreger, D.M. 1991. Aging, inhibitory processes and negative priming. J. Gerontol. 46:340-345.

McDowd, J.M., Oseas-Kreger, D.M., and Filion, D.L. 1995. Inhibitory processes in cognition and aging. In Interference and inbibition in cognition (eds. F.N. Dempster and C.J. Brainerd), pp. 363-400. Academic Press, San Diego, CA.

McEnaney, K.W. and Butter, C.M. 1969. Perseveration of responding and nonresponding in monkeys with orbital frontal ablations. J. Comp. Physiol. Psychol. 68:558-561.

Means, L.W. and Holsten, R.D. 1992. Individual aged rats are impaired on repeated reversal due to loss of different behavioral patterns. Physiol. Behav. 52:959-963.

Menon, V., Adleman, N.E., White, C.D., Glover, G.H., and Reiss, A.L. 2001. Error-related brain activation during a go/no-go response inhibition task. Hum. Brain Mapp. 12:131-143.

Milgram, N.W., Head, E., Weiner, E., and Thomas, E. 1994. Cognitive functions and aging in the dog: Acquisition of nonspatial visual tasks. Behav. Neurosci. 108:57-68.

Mishkin, M. 1964. Perseveration of central sets after frontal lesions in monkeys. In The frontal granular cortex and behavior (eds. J.M Warren and K. Akert), pp. 219-241. McGraw-Hill, NY.

Moscovitch, M. and Winocur, G. 1995. Frontal lobes, memory, and aging In Structure and functions of the buman prefrontal cortex (eds. J. Grafman, K. Holyoak, and F. Bohler), pp. 119-150. New York Academy of Sciences, NY.

Nielson, K.A., Langenecker, S.A., and Garavan, H. 2002. Differences in functional neuroanatomy of inhibitory control across adult life span. Psychol. Aging 17:56-71.

Oscar-Berman, M. and Zola-Morgan, S.M. 1980. Comparative neuropsychology and Korsakoff's syndrome: Spatial and visual reversal learning. Neuropsychologia 18:499-512.

Persad, C.C., Abeles, N., Zacks, R.T., and Denburg, N.L. 2002. Inhibitory changes after 60 and their relationship to measures of attention and memory. J. Gerontol. 57:223-232.

Rapp, P.R. 1990. Visual discrimination and reversal learning in the aged monkey. Behav. Neurosci. 104:876-884.

Rahner-Welsch, S., Frölich, L., Stoll, S., and Hoyer, S. 1995. Decline and preservation of reversal learning abilities and acquisition in the course of senescence. Neurosci. Lett. 194:121-123.

Rebai, M., Bernard, C., and Lannou, J. 1997. The Stroop's test evokes a negative brain potential, the N400. Int. J. Neurosci. 91:85-94.

Roberts, A.C, Robbins, T.W., and Weiskrantz, L. 1998. The prefrontal cortex: Executive and cognitive functions, pp. 222-242. Oxford University Press, NY.

Rolls, E.T. 1998. The orbitofrontal cortex. In The prefrontal cortex: Executive and cognitive functions (eds. A.C. Roberts, T.W. Robbins, and L. Weiskrantz), pp. 67-86. Oxford University Press, London.

Rolls, E.T. 2000. The orbitofrontal cortex. Cereb. Cortex 10:284-294.

Sasaki, K. and Gemba, H. 1986. Electrical activity in the prefrontal cortex specific to no-go reaction of conditioned hand movement with color discrimination in the monkey. Exp. Brain. Res. 64:603-606.

Settlage, P., Zable, M., and Harlow, H.F. 1948. Problem solution by monkeys following bilateral removal of frontal areas: VI. Performance on tests requiring contradictory reactions to similar and identical stimuli. J. Exp. Psychol. 38:50-65.

Siwak, C.T., Tapp, P.D., and Milgram, N.W. 2002. Effect of age and level

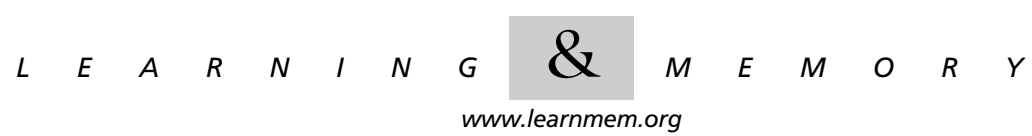


of cognitive function on spontaneous and exploratory behaviors in the beagle dog. Learn. Mem. 8:317-325.

Spieler, D.H., Balota, D.A., and Faust, M.E. 1996. Stroop performance in healthy young and older adults and in individuals with dementia of the Alzheimer's type. J. Exp. Psychol. Hum. Percept. Perform. 22:461-479.

Strong, P.N., Drash, P., and Hedges, M. 1968. Solution of dimension abstracted oddity as a function of species, experience, and intelligence. Psychon. Sci. 11:337-338.

Stroop, J.R. 1935. Studies of interference in serial verbal reactions. J. Exp. Psychol. 18:643-661.

Sutherland, N.S. and Mackintosh, N.J. 1971. Mechanisms of animal discrimination learning, pp. 24-48. Academic Press, NY.

Sweeney, J.A., Rosano, C., Berman, R.A., and Luna, B. 2001. Inhibitory control of attention declines more than working memory during normal aging. Neurobiol. Aging 22:39-47.

Tapp, P.D., Holowachuk, D., Siwak, C.T., and Milgram, N.W. 2001. Size really does matter: Concept use in aging. Abstr. Soc. Neurosci. 31:533.7

Tapp, P.D., Siwak, C.T., Chiou, G., Black, S.E., McCune S., Head, E., Cotman, C.W., Milgram, N.W., and Su, Y-M. 2002. Effects of age on frontal and hemispheric brain symmetry in the beagle dog. Abstr. Soc. Neurosci. 28:374.9.

Thomas, R.K. and Frost, T. 1983. Oddity and dimension-abstracted oddity (DAO) in squirrel monkeys. Am. J. Psychol. 96:51-64.

Tighe, T.J. 1964. Reversal and nonreversal shifts in monkeys. J. Comp. Pbysiol. Psychol. 58:324-326.

Tsuchida, J., Kubo, N., and Kojima, S. 2002. Position reversal learning in aged Japanese macaques. Behav. Brain Res. 129:107-112.

Vendrell, P., Junqué, C., Pujol, J., Jurado, M.A., Molet, J., and Grafman, J.
1995. The role of prefrontal regions in the Stroop task. Neuropsychologia 33:341-352.

Voytko, M.L. 1993. Cognitive changes during normal aging in monkeys assessed with an automated test apparatus. Neurobiol. Aging 14:643-644.

Voytko, M.L. 1999. Impairments in acquisition and reversal of two-choice discriminations by aged rhesus monkeys. Neurobiol. Aging 20:617-627.

Walker, L.C., Kitt, C.A., Struble, R.G., Wagster, M.V., Price, D.L., and Cork, L.C. 1988. The neural basis of memory decline in aged monkeys. Neurobiol. Aging 9:657-666.

Wallis, J.D., Dias, R., Robbins, T.W., and Roberts, A.C. 2001. Dissociable contributions of the orbital and lateral prefrontal cortex of the marmoset to performance on a detour reaching task. Eur. J. Neurosci. 13:1797-1808

West, R. and Alain, C. 2000. Age-related decline in inhibitory control contributes to the increased Stroop effect observed in older adults. Psychophysiology 37:179-189.

West, R. and Baylis, G.C. 1998. Effects of increased response dominance and contextual disintegration on the Stroop interference effect in older adults. Psychol. Aging 13:206-217.

Zacks, R.T. and Hasher, L. 1994. Directed ignoring: Inhibitory regulation of working memory. In Inbibitory processes in attention, memory, and language (eds. D. Dagenbach and T.H. Carr), pp. 241-264 Academic Press, San Diego, CA.

Received July 24, 2002; accepted in revised form November 21, 2002.

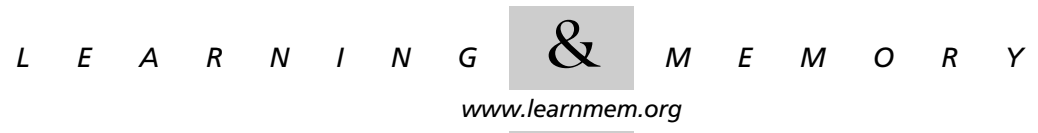




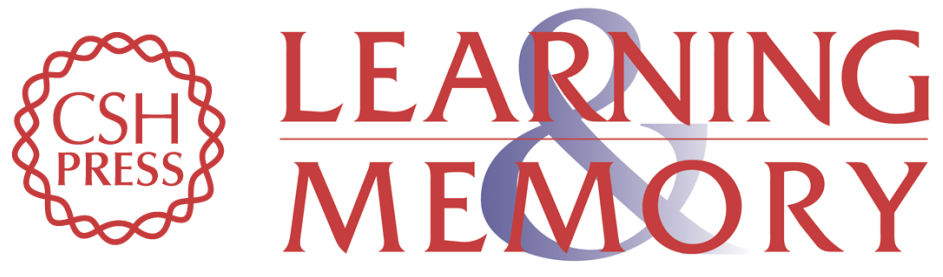

\section{Size and Reversal Learning in the Beagle Dog as a Measure of Executive Function and Inhibitory Control in Aging}

P. Dwight Tapp, Christina T. Siwak, Jimena Estrada, et al.

Learn. Mem. 2003, 10:

Access the most recent version at doi:10.1101/lm.54403

References This article cites 81 articles, 4 of which can be accessed free at: http://learnmem.cshlp.org/content/10/1/64.full.htmI\#ref-list-1

License

Email Alerting Receive free email alerts when new articles cite this article - sign up in the box at the Service top right corner of the article or click here. 